\title{
Intracisternal A-Particle
}

National Cancer Institute

\section{Source}

National Cancer Institute. Intracisternal A-Particle. NCI Thesaurus. Code C13374.

Retroviral-like intracisternal A particles. High copy number family of repeated elements in the mouse with a typical proviral organization. Expressed very early in mouse development ( $2-8$ cell stage) and in transformed cells. Mutant alleles of various genes contain newly-integrated IAP genes. 